\title{
Enhancing Coordination for Effective Management of Oil Spill Pollution in South Africa
}

\author{
Phindile Tiyiselani Zanele Sabela-Rikhotso $^{1} \cdot$ Dewald van Niekerk $^{1}$. \\ Livhuwani David Nemakonde ${ }^{1}$
}

Accepted: 20 January 2022/Published online: 8 February 2022

(C) The Author(s) 2022

\begin{abstract}
Although multi-sectoral coordination in disaster risk management has been progressing in South Africa for over two decades, there has been limited commitment to an integrated regime in managing marine oil spill incidents. Poor incident management persists despite the availability of data, protocols, legislation, and resources housed in different government and private sector entities. This study identified practices that enhance a coordination process for the effective management of oil spill pollution. A grounded theory approach is applied to the coordination issue, which is characterized by an interactive process of simultaneously considering theoretical grounding during our empirical research. Empirical evidence includes observations of 47 meetings and three oil spill exercises with 79 delegates from 32 different organizations, which supports the coordination process of instituting a national Incident Management System for marine oil spills in South Africa. An additional 44 individual open-ended questionnaires supplement this earlier body of evidence for data triangulation and validation. Analysis of development of the Incident Management System process revealed that, when designing a novel long-term project that is reliant on a shared vision from multiple organizations, enhanced coordination and collaboration for successful implementation is dependent on the following practices: (1) obtaining political commitment, (2) bridging knowledge gaps, and (3) sharing resources.
\end{abstract}

Phindile Tiyiselani Zanele Sabela-Rikhotso phiphi.sabela@gmail.com

1 African Centre for Disaster Studies, North-West University, Potchefstroom 2531, South Africa
Keywords Government-industry cooperation · Incident management system $\cdot$ Marine oil spills $\cdot$ Operation Phakisa $\cdot$ South Africa

\section{Introduction}

Shared values, collective cognitive resources, commitment, and trust are tested to the limit during disaster response operations. This compatibility is particularly difficult to attain for professionals from different emergency organizations, and sometimes its absence results in poor decision making with unintended consequences. Unexpectedly severe incidents, opposing interests, mistrust, non-cooperation among members of the incident response team, disrupted chain of commands, and inadequate understanding of the unfolding situation are elements that have often challenged the implementation of existing contingency plans and institutional structures (Dwivedi et al. 2018). Several significant incidents worldwide have demonstrated that these conflict elements often result in ambiguities and consequent disintegrated incident management efforts (Comfort and Kapacu 2006). Nevertheless, Wolbers et al. (2018) opine that this form of fragmentation is essential in encouraging professionals to devise novel actions that will enable effective coordination. It can thus be argued that coordination is realized when there is a straightforward process of merging a set of disaggregated activities and actions into uniform arrangements. These may include multiple interpretations of the same system and ad hoc adaptations. This study identified, through the Operation Phakisa B1 initiative, practices that enhance a coordination process to manage effectively oil spill pollution in South Africa. 
Operation Phakisa is a presidential initiative adopted from the Malaysian government's Big and Fast Methodology, and is aimed at fast tracking development (Odeku 2021). Considering the country's high level of poverty, unemployment, and crime, President Jacob Zuma has implemented the South African version of this initiative, renaming it "Operation Phakisa." Phakisa is a Sesotho word that means "hurry up." While Operation Phakisa focused on ensuring tangible plans, monitoring and evaluation were crucial to ensure that progress is transparent to the public. The B1 initiative specifically was undertaken by experts from both government and industry to identify environmentally sustainable ways of maximizing safety in the field of oil and gas exploration and exploitation in order to grow the oceanic contribution (the blue economy) to South Africa's economy. ${ }^{1}$

This form of coordination contributes to social network theory, focusing on how entities may effectively collaborate during the preparedness and planning phases (planned network), which may eventually enhance the existing network during emergency response. This article further contributes to the coordination literature in marine oil spill management through the incident command system (ICS) lens, which has been fully adopted for managing marine oil spills through the newly updated National Oil Spill Contingency Plan (NOSCP).

\section{Network Governance for Managing Complex Issues}

Recent theoretical development in coordination systems points to the need for a paradigm shift from descriptive interpretation to process analysis. Simultaneous synchronization of interdependent trajectories requires informative theoretical analysis to guide "how" this can be achieved (Wolbers et al. 2018). In a marine oil spill context, clarifying institutional interaction patterns and functions with factors interdependent to environmental linkages may be well understood by applying a network governance approach. Network governance is defined as coordination categorized by an informal societal arrangement conceptualized by relationship building and casual information sharing rather than a bureaucratic, hierarchical system (Jones et al. 1997). Grönholm (2018) submits that network governance indicates a transition towards adaptive collaboration in managing complex issues that require fluid

\footnotetext{
${ }^{1}$ Operation Phakisa B1 Initiative: Oceans Economy set out the preparatory work for the development of the Interim IMOrg (Incident Management Organization) that was constituted on 25 October 2017. Thus, any reference to the B1 initiative or Operation Phakisa also refers to the Interim IMOrg since the research was conducted with the team through the transition.
}

relations and innovative solutions. Governance networks may be formed to address a particular policy challenge with formalized networks and official terms of references in place. Secondly, networks may be formed through informal inter- or intra-organization of role players.

Like the principles of ICS, the network approach requires streamlined multiple nodes of reporting and communication to minimize conflict and misinterpretation of information (Noori et al. 2016). While ICS provides valuable guidance on how incident management activities ought to be handled, the failure and success of the system in the same manner as the network approach depend on collaborative decision making. Incident command systemrelated collaboration requires a favorable atmosphere created on the premise of a social matrix and led by trust resulting from prior relations. Social matrix is defined in human behavioral traits, including socialization, cultural behavior, religious practices, and social class (Bunge and Ardila 1987). These are qualities that are also crucial in network governance because human interaction through working and staying together is a prerequisite in communication development (Shibutani 2017). It can thus be argued that improved lines of communication amidst operative personnel and senior managers (strategy drafters) is critical for meaningful collaborative decision making. This nature of collaboration may be enabled through an Incident Management System (IMS) designed with the ability to efficiently amalgamate communication (Bahrami et al. 2020) and provide an information management system (Rice 2009). However, this is challenging for emergency services such as firefighting, policing, and oil spill mitigation, where rapid response is a priority (Bigley and Roberts 2001).

\section{From Incident Command System Towards an All-Hazard Institutionally Integrated System}

The evolution of the incident command system (ICS) is classified into three main eras: the functional origin; voluntary adoption; and mandatory diffusion (Moynihan 2009). The functional origin of ICS is linked to the challenges experienced in responding to wildfires that raged in California in the 1970s. Lack of structure for coordinated planning among responding agencies, unclear and multifaceted lines of authority, and incoherency in terminology, were some of the functional challenges that the system was originally designed to address (Buck et al. 2006).

The second phase in the development of ICS, voluntary adoption, is characterized by the willingness of sectors beyond forest fire fighting to adopt the system. Implementation of the system throughout emergency services thus far is associated with the international best practices 
for prioritizing incident response objectives. Boersma et al. (2014) list saving lives, protecting property, and continuing public services in descending order of priority in designing incident response objectives. It can thus be argued that generic relevance and international recognition of these priorities has enabled the voluntary adoption of the system beyond the borders of the United States and Canada.

The third and final stage of ICS development is mandatory diffusion. This stage resulted from the two policy statements, the National Incident Management System and the National Response Plan intended to nationalize crisis management in the United States (Moynihan 2009). In recent years, many countries and regions, including India, Taiwan, Japan, South Africa, Namibia, and Botswana, have adopted the mandated system in varied forms (Okada and Ogura 2014; Chang 2015; Sharma et al. 2015).

In the context of marine oil spill response, however, the adoption of the ICS was a consequence of the 1989 MT Exxon Valdez oil spill in March 1989. This event was also notable in leading to the enactment of the Oil Pollution Act of 1990. The first use of oil spill implementation of ICS in the United States was during the American Trader nearshore oil spill off Huntington Beach, California incident response in 1990 (Rolan and Cameron 1991).

Analysis of the nature of ICS and the contributing effectiveness of its theoretical development is likewise crucial for understanding its evolutionary trend. In the multi-agency emergency management spectrum, there is a consensus that the response pattern of hierarchy and centralization is shifting towards a more collaborative, decentralized, flexible, and network coordinated structure (Lutz and Lindell 2008; Moynihan 2009). In the same way, the whole continuum of incident management requires an unconventional theoretical conceptualization of the coordination theory. This theory underlines that coordination is equally important in response, preparedness, and possibly recovery and rehabilitation stages. Emergent coordination theorizes coordination as a notion based on integration. Integrative conditions are thus dependent on accountability, predictability, and common understanding resulting from efficient communication. This is because stakeholders require shared resources, structured roles, shared expectations, a system of workflow, and collective use of resources. In acknowledging these coordination characteristics, this study then analyzed the following fundamental factors:

- Political commitment for building vision-driven coherence and common goals;

- Gap analysis to clarify, educate, and reach a common understanding in terms of all building blocks intended for a successful vision; and
- Shared incident management resources (expertise and equipment)

\section{Methodology}

In this study, an interactive grounded theoretical approach is applied to the mainstream coordination factor, which is considered concurrently with the field observation and interviews. This approach is valuable for analyzing organizational operations and research participants' actions and perspectives throughout the data collection process (Thornberg 2017).

\subsection{Data Collection}

Data were collected from the engagements of the presidential initiative Operation Phakisa B1 working group and task team meetings conducted from November 2016-April 2018 in Cape Town, South Africa. A total of 47 interactions (meetings) of oil spill managers in conducting the Operation Phakisa B1 initiative were observed to note and study the participants' interactions and behavior without interfering with their operational work. This further allowed analysis of challenges and opportunities as they unfolded throughout these series of meetings and exercises. The interviews were held in all four coastal provinces in South Africa-Northern Cape, Western Cape, Eastern Cape, and KwaZulu Natal. Two exercise observations were carried out in Cape Town and one in Algoa Bay, Eastern Cape Province. In addition to the detailed recording of these interactions, post-exercise debriefings and interviews with participants were transcribed.

The interviewees reflected on their experiences and perspectives of the Operation Phakisa B1 meetings and the exercises conducted. Combining the two data collection methods were crucial to ensure clarification and simplified stakeholder interaction.

Data were collected in three phases: the pilot phase, the main data collection, and the validation phase. These phases consisted of two steps-a meeting (engagement), followed by individual interviews to validate and triangulate the observed data. During the pilot phase, a total of four interactions (sessions) of oil spill managers who were conducting the Operation Phakisa B1 initiative were observed, followed by four individual interviews. The main data collection phase consisted of 47 observation events (Table 1) and 40 semistructured interviews with experts in oil spill management (Fig. 1). Experts consisted of individuals at various positions (management, technical, and operational) within their respective organizations. Participants were selected through a purposive sampling 
Table 1 Summary of Operation Phakisa B1 working group meetings from November 2016-April 2018 in Cape Town, South Africa

\begin{tabular}{ll}
\hline Information & Total counts \\
\hline Number of meetings & 47 \\
Total number of organizations & 32 \\
Number of delegates & 79 \\
Number of government organizations & 15 \\
Number of oil industry organization & 15 \\
Number of nongovernmental organizations & 1 \\
Number of state owned entities (SOE) (Parastatals) & 1 \\
\hline
\end{tabular}

technique that included experts from the internationally recognized oil industry, ship captains, and managers within different government agencies and nongovernmental organizations (NGOs). The competence of these individuals is the culmination of decades of disaster risk management, marine and environmental sciences training, and practical experience in managing marine oil spills. Lastly, interviews with experts who participated in these exercises in the validation phase followed an observation of three oil spill response exercises.
Member checks were necessary (Schwartz-Shea and Yanow 2009) to verify that the recorded perspectives were in line with the views and operational experience of the participants. The combination of validation methods employed in this study reflect the process assumed for instituting an Incident Management System.

\subsection{Data Analysis}

This study considered a broad range of resources. Therefore, the analysis of the findings was characterized by a process that progressively extended and interrelated the insights accumulated throughout the three phases of data collection. The study analysis was based on theoretical sampling. A QDA Lite software analysis tool was applied to assign codes to aspects of importance during the exercises and meetings, as well as interaction with participants during the interviews. Initially, the main themes of this study were identified by aligning our preliminary ideas, research notes, and minutes.

The research team comprehensively conducted an allinclusive approach to assess a coordination process with open coding to rationalize the data. This was achieved by focusing on occurrences where participants, explicitly or implicitly, exhibited an influence of certain factors that

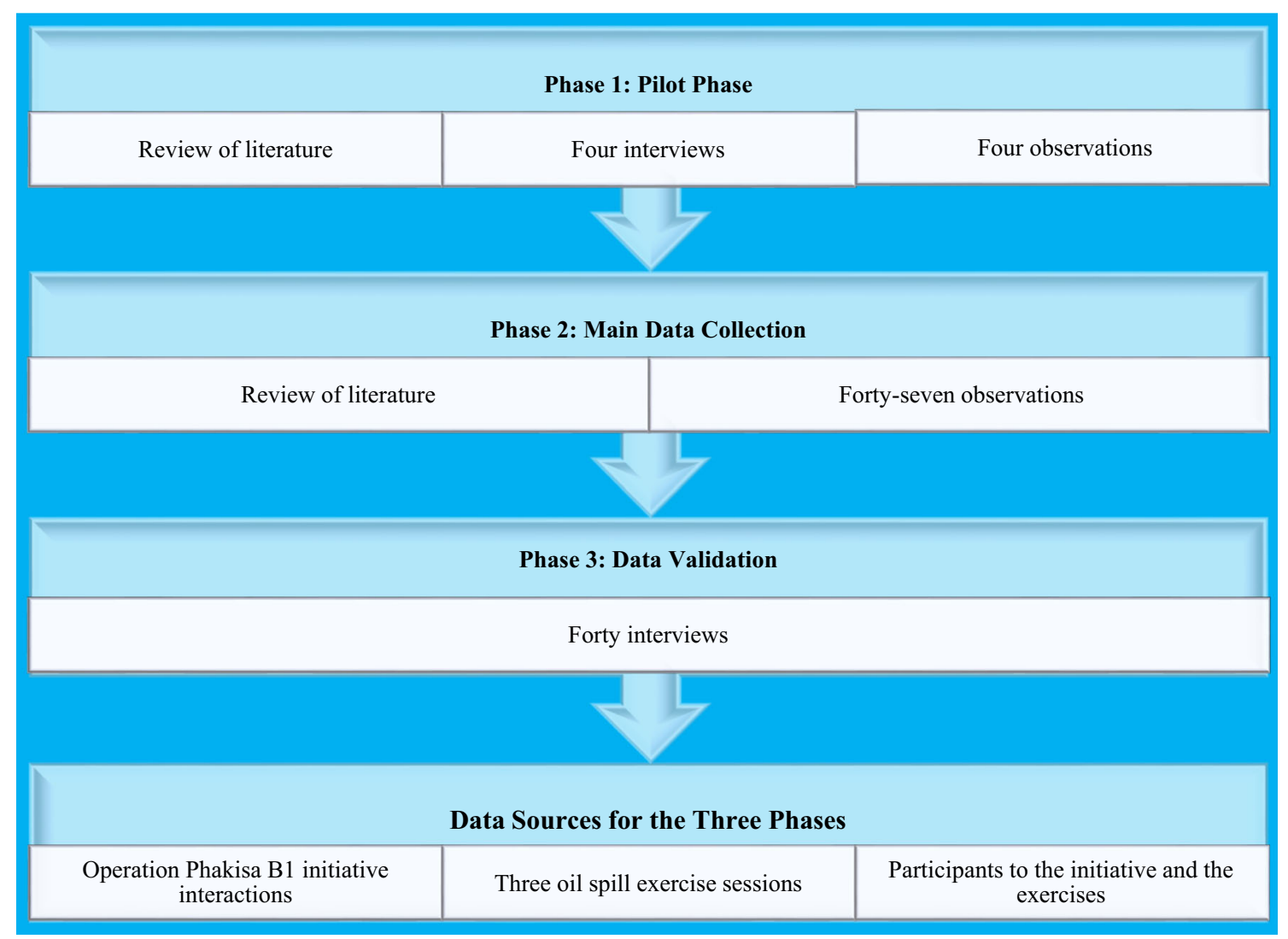

Fig. 1 Research design for the study of effective oil spill management in South Africa 
hinder or enhance the multi-sector coordination process. Contextual misperception of roles and responsibilities, sharing of workload, and sustainable relations provided an initial idea of essential aspects for coordination. A detailed analysis was then conducted through axial coding to define and clarify connections between the codes and themes.

The data analysis structure (Table 2) undertook the following sequences. First, data collected through the methods detailed in Sect. 4.1 were analyzed and catalogued as the first order raw data. Based on this initial categorization, the 2nd order analysis sought to identify common triggers that influenced the recorded 1 st order data. The 3 rd and 4th order analyses answered the questions respectively: What are the requirements? What responsive task must be taken to ensure effective coordination practices in marine oil spill management? Thus, coordination practices (main themes) followed a specific sequence-setoffs that led to requirements, which resulted in responsive tasks.

In analyzing the validation phase data, the relationship between themes and the codes illustrated three setoffs that reappeared in all data sources: (1) fragmented legislative mandates, (2) limited knowledge and understanding of marine oil spill, and (3) lack of experience and specialized training. The research team then developed a data structure based on these setoffs and details from the observations and interviewees' responses. Further analysis of these responses provided insights into our data structure. It was clear that these setoffs may be categorized into three diverse practices_-gaining political commitment, bridging knowledge gaps, and sharing resources.

The data structure (Table 2) enabled critical evaluation, comparison, and validation of the understanding of the coordination process observed in the meetings and exercises. Findings were validated through post-observation interviews, minutes, and exercise debriefing reports. Detailed analysis of this material minimized the deterministic application of the coding system throughout the model structuring process. Alternative explanations were thus pursued to understand the unwillingness of stakeholders to adopt a new, untested approach.

\section{Findings}

Analysis of the Incident Management System (IMS) development process revealed that several practices must be in place before designing a novel, unbudgeted long-term multi-stakeholder collaboration project. These essential

Table 2 Data analysis structure for the study of effective oil spill management in South Africa

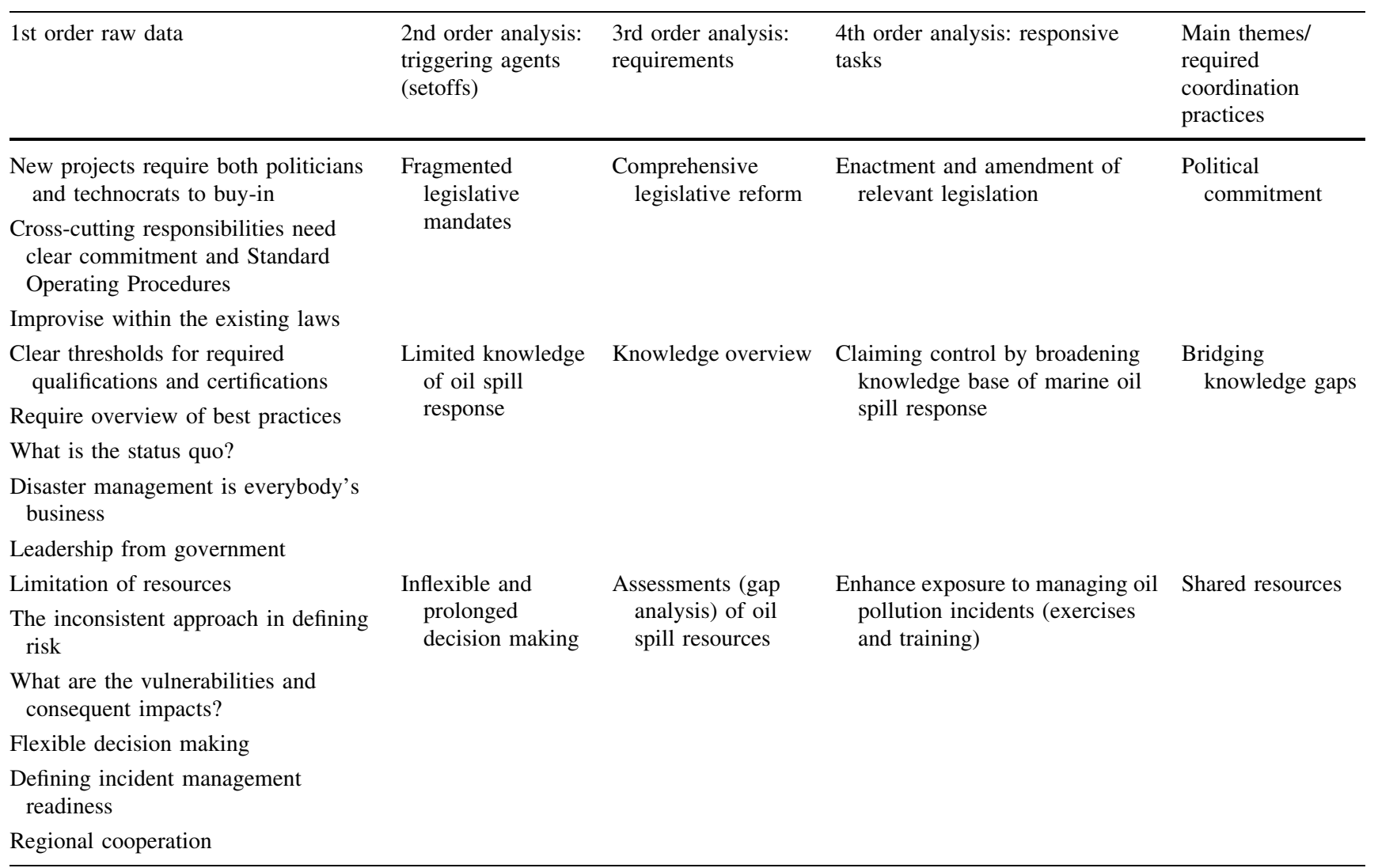


variables are: (1) political commitment, (2) bridging knowledge gaps, and (3) sharing of resources-the main themes and required coordination practices are identified in the last column of Table 2. These practices enabled the participating organizations to reform the legislative outlook of the country, broaden knowledge and understanding of marine oil spill response, and enhance exposure to managing such incidents. Subsequently, in this section, each practice is discussed with a particular focus on how the setoffs enabled an innovative task, which eventually enhanced and shaped an ideal coordination process, to develop an IMS for marine oil spills.

\subsection{Political Commitment for Building a Vision- Driven Coherence and Common Goals}

The South African government is politically committed to oil spill management. Following the research observation of the presidential Operation Phakisa initiative, it is evident that there has been considerable will to create clarity in the legislative framework for the marine oil and gas industry. The government has endeavored to create a qualifying investment for this capital-intensive sector by streamlining and regulating the licencing processes for oil and gas exploration and production and by operationalizing the International Oil Pollution and Compensation Fund. Additionally, the government further advocates for research opportunities that will disclose information beneficial in managing endangered ecosystems, marine resources, and ocean renewable energy through this initiative.

Finally, the government organized joint governmentindustry emergency response drills and exercises to initiate an adequate oil spill response capacity for renewable five year periods, beginning in 2016. This study focussed specifically on this planning and response effort. Following the work related to rolling out these oil spill exercises and drills, many tasks had to be undertaken through a working group named Operation Phakisa Ocean Economic Oil and Gas Lab (B1). This working group is a presidential initiative to conduct Joint Industry-Government Emergency Response Drills over five years (2016-2021). Multiple deliverables intended to enable effective capacity building drills and exercises were identified in a detailed action plan named the "3-ft plan." These included developing the National Oil Spill Contingency Plan, gap analyses in managing marine oil spill pollution, and strengthening multi-stakeholder coordination of resources.

The Department of Forestry, Fisheries and the Environment (DFFE) managed this initiative with several government departments and companies with roles and responsibilities in the marine oil and gas industry by encouraging collaboration in a working group and a few task-specific teams. These arrangements were officiated by the institutionalization of the IMS as the concept for oil and gas emergency response in South Africa. Incident Management System structure (Fig. 2) was thus endorsed on 25 October 2016 by the Operation Phakisa Oceans Economy Ministerial Management Committee.

In observing the interactions of the working groups in delivering the tasks listed above, several government officials were of the view that the work accepted by the Ministers is outside their respective legislative scopes. Although the political commitment may be deduced, the practicality of the commitment was rather complex. A municipal official validated this observation during an interview, and the matter was highlighted as follows: "We have to do our daily roles and responsibilities as stated in the job description; additional collaborative projects are strenuous and expand my scope without any tangible budget nor incentive" (Respondent 3).

In addition to limited human resources, the lack of financial commitment indicates a potentially limited political commitment. The participating private sector, on the other hand, equally questioned the validity of the authoritative powers vested on various associate organizations, such as the Offshore Petroleum Association of South Africa (OPASA), the South African Petroleum Industry Association (SAPIA), and the South African Oil and Gas Alliance (SAOGA), to commit individual companies to binding legal decisions. Nonetheless, "industry is fully committed to this process because this is the first time that industry had thoroughly participated in the drafting of the National Oil Spill Contingency Plan (NOSCP)..." (Respondent 4).

Moreover, there were unclear and poorly communicated political visions signaled to administrative executives before the implementation phase. This had the potential to instigate conflict due to task misinterpretation, thus undermining the intended multi-sector coordination vision. This challenge was detailed during one of the interviews as follows: "It was often difficult to construe some of the activities listed in the 3-ft-plan; we had to intentionally focus on the envisaged end goals rather than providing prescriptive tasks to avoid conflict" (Respondent 1).

Regardless of a well-thought-out process for developing any initiative, an organization is affected by its legislative mandate and the common understanding of risk between politicians and government officials. Observations thus allowed for an interrogation of the legitimacy of particular institutions or representatives to undertake the roles assigned through the initiative. Moreover, during the early stages of the initiative, the project was perceived to lack legislative legitimacy other than that it was an obligatory presidential directive. Thus, the operationalization of the 
Fig. 2 Institutional arrangements for managing marine oil spills in South Africa. DMR Department of Mineral Resources, DOE Department of Energy, PASA Petroleum Agency South Africa, DOT Department of Transport, SAMSA South African Safety Agency, NDMC National Disaster Management Centre, DEA Department of Environmental Affairs (currently known as the DFFE Department of Forestry, Fisheries and Environment). Source https://www.slideshare. net/DurbanChamber031/ environmental-affairs-forumcurrent-and-future-of-oil-spillresponse-9

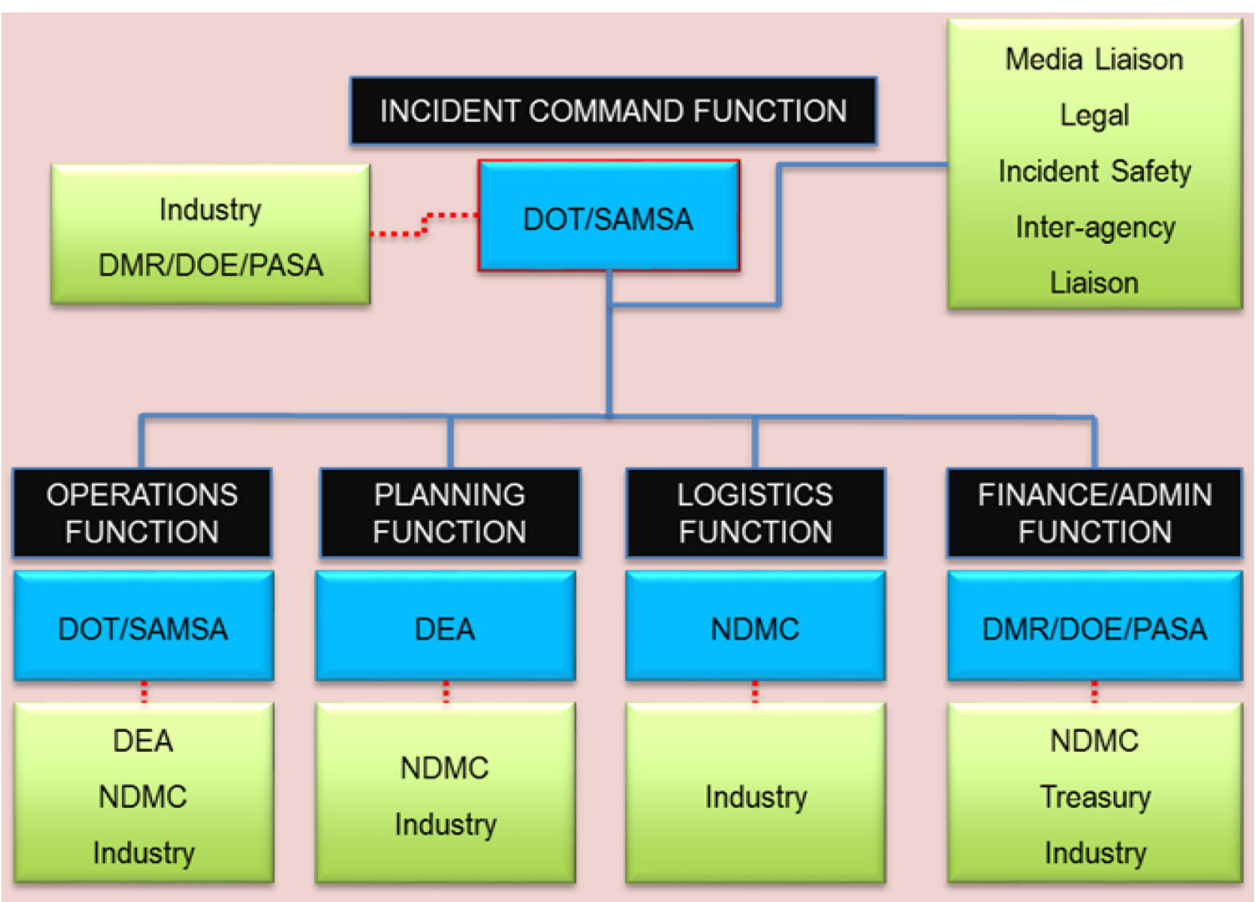

International Oil Pollution Compensation Fund laws provided some tangible benefit from the initiative.

The findings showed that regardless of the legislative obligation for multi-agency collaboration and shared understanding, unison implementation of the vision will not be effective without a joint political commitment. Moreover, the study findings indicate the observed reservations in accepting shared roles and responsibilities. A holistic analysis of knowledge gaps, undertaken to enhance the incident management system for oil spills, was subsequently considered to resolve these challenges.

\subsection{Bridging Knowledge Gaps}

Considering the array of organizations with numerous roles in managing marine oil spills, it is understandable that there would be knowledge gaps within the existing management system. Observational data from the exercises exposed limited transfer of information among participants. This limitation impacted the development of the exercise processes and had negative performance consequences. This observation was validated during an interview session: "Working together during the drills and training together is brilliant for bridging the knowledge gap, but it is difficult to attain because it is often difficult to easily accept alternative perspectives" (Respondent 10).

Accordingly, obtaining knowledge beyond one's usual network provides an opportunity to stimulate creative ways of solving problems. In observing the engagements of working group members during their weekly meetings, it was clear that sensible, innovative ways of drafting the national oil spill contingency plans were established. To this extent, the working group went beyond the scope of the 3 -ft plan by developing a detailed, independent, oil spill response plan to minimize impacts on wildlife. In particular, the national oil spill contingency and the oil spill impacts on wildlife plans specify the frequency with which exercises should be conducted to guarantee and accredit the skill level and experience that oil spill experts must possess to handle future incidents effectively.

On the other hand, novelty encouraged through this form of coordination is dependent on an understanding of each other's legal mandates and capacities. The working group was observed to collectively and organizationally assess progress in implementing their legislative mandate. This process was perceived to be a crucial factor in providing an opportunity for legislative awareness and allowing meaningful participation in the implementation of legal reform.

Regardless of this effort, an uncoordinated knowledge gap analysis undermines the capacity-building endeavor. This coordination deficit caused cross-sectoral inconsistencies in the methods adopted by different organizations, resulting in inaccurate information and a subsequent weak risk profile. Essentially, this disfunction undermines the systematic prioritization and sharing of resources.

It can thus be argued that understanding the existing knowledge gaps and striving to bridge them is vital in identifying strategic inefficiencies. Expectedly, constant and continued effort to attain actionable, sustainable solutions for cross-cutting roles and responsibilities was 
recognized, setting off the third practice in establishing sustainable links for coordination—sharing resources.

\subsection{Sharing of Resources}

Sharing resources is vital in disaster risk management, particularly in ensuring efficient and integrated preparedness and response. Findings of the exercise observation data revealed that coordination through sharing of resources enhances management of marine oil spills. In validating this, an interviewee expressed the viewpoint that "interactions during an exercise creates a friendship that will make sharing oil spill equipment easy" (Respondent 5). This respondent further said that before the first exercise, "I had no idea what resources are available where this made the exercise participation difficult." Thus, the DFFE developed an oil spill management dashboard software to resolve this challenge through working group engagements (GIWACAF 2019). Among other things, the dashboard housed data regarding the operability and location of oil spill equipment, contact details of experts, and upcoming capacity building initiatives such as training and exercise programs.

Observations of the working group engagement established that sharing intellectual, funding, and human resources is invaluable for multi-sectoral institutional coordination. During the exercise, these qualities significantly advanced and strengthened the oil pollution preparedness regime in South Africa. Regardless of the value realized, inequitable and ineffective investment in environmental rehabilitation and monitoring resources persists.

Summarily, both observation and individual interview findings demonstrate that human resources, information, material, and financial resources were sequentially the most shared. These resources are categorized into materials (for example, equipment), human (for example, experts and personnel), information (for example, expertise, contacts, training and exercise opportunities), and financial resources (for example, joint funded projects) (Opdyke et al. 2017). It may be argued that this enhancement is associated with the concepts of the Unified Command System adopted within the newly established institutional arrangements (Fig. 2).

Several government agencies indicated that they participate in policy development and exercises and training focused on oil spill management. Despite this, they typically would not, in practice, assume responsibility for nor participate in an operational oil spill response and recovery activity. This is because the legal mandates are often questioned where resources ought to be committed. "It is easy to work with entities during the peaceful time, but during a response, it is extremely hard to coordinate, especially due to financial implications" (Respondent 7). In line with this perspective, it is evident that although organizations train and exercise collectively, with an opportunity to attain synchronized experience and strengthen information and communication systems, marine oil spill response coordination may nevertheless be undermined without collective funding commitment.

Findings also highlighted that the willingness of stakeholders to constantly participate and positively contribute to the activities of the project is a good indicator of readiness to share resources. Expertise and donations for logistical arrangements to conduct marine oil spill response exercises were some of the resources shared, particularly from the oil industry operating in South Africa. "Operation Phakisa B1 demanded flexibility in our approach, especially in sourcing resources whether it was overseas expertise, donations or sponsorship from the oil industry for success" (Respondent 11).

Moreover, several regional collaborations, including a training program for Eastern African Countries on Oil Pollution: Shoreline Assessment \& Response, Tanzania in 2018; and the 8th Global Initiative for West, Central and Southern Africa Project (GIWACAF) conference of 2019 are some of the examples that participants believed to have enhanced the sharing of resources. These events resulted in perceptible action plans and agreements intended to strengthen oil spill preparedness and response across the region. A respondent reflected as follows after attending the conference in Tanzania: "our [referring to the South African government] participation on international exercise platforms not only improves cooperation between government and the oil industry but opened our minds in ensuring tangible action plan" (Respondent 2).

Considering that the foundation of Operation Phakisa Initiative B1 was undertaken to facilitate marine oil spill readiness in anticipation of the booming blue economy in South Africa, the resourcefulness of this initiative was probed. The general perspective of the respondents is that the initiative provided opportunities for collaborative capacity building in terms of cross-sectional training, streamlining of policy objectives, and commitment to multi-faceted memoranda of agreements for an institutionalized management system in the country. Nevertheless, the study outlined resistance to sharing resources for response operations with financial implications, mainly where the legal mandate to do so is ambiguous.

\section{Discussion}

Findings provided insights into the coordination practices adopted throughout the lifecycle of the Operation Phakisa B1 initiative. The coordination practices adopted were triggered by fragmented and ambiguous legislative mandates, limited knowledge and experience in managing oil 
Table 3 A process model of coordination practices for a long-term incident management project developed in South Africa through the Operation Phakisa B1 initiative

\begin{tabular}{|l|l|l|l|l|}
\hline $\begin{array}{l}\text { Integration / } \\
\text { Institutional } \\
\text { Collaboration } \\
\text { Enablers }\end{array}$ & Setoffs & Requirements & $\begin{array}{l}\text { Coordination } \\
\text { Practice for } \\
\text { Efficient } \\
\text { Management } \\
\text { System }\end{array}$ & Resourcefulness \\
\hline Predictability & $\begin{array}{l}\text { Fragmented } \\
\text { legislative } \\
\text { mandates }\end{array}$ & $\begin{array}{l}\text { Comprehensive } \\
\text { legislative } \\
\text { reform }\end{array}$ & $\begin{array}{l}\text { Political } \\
\text { commitment }\end{array}$ & $\begin{array}{l}\text { Monitoring and } \\
\text { evaluation }\end{array}$ \\
\hline $\begin{array}{l}\text { Shared } \\
\text { Accountability }\end{array}$ & $\begin{array}{l}\text { Limited } \\
\text { knowledge in } \\
\text { oil spill } \\
\text { response }\end{array}$ & $\begin{array}{l}\text { Knowledge } \\
\text { overview }\end{array}$ & $\begin{array}{l}\text { Bridging the } \\
\text { gaps }\end{array}$ & $\begin{array}{l}\text { Innovative problem- } \\
\text { solving skills }\end{array}$ \\
\hline $\begin{array}{l}\text { Common } \\
\text { Understanding }\end{array}$ & $\begin{array}{l}\text { Inflexible and } \\
\text { prolonged } \\
\text { decision } \\
\text { making }\end{array}$ & Assessment & $\begin{array}{l}\text { Resource } \\
\text { sharing }\end{array}$ & $\begin{array}{l}\text { Collaborative capacity } \\
\text { building }\end{array}$ \\
\hline
\end{tabular}

spills, and inflexible and prolonged decision-making processes. The stakeholders responded to these difficulties by engaging in coordination practices that allowed for a continuous gap analysis exercise that resulted in three resourcefulness characteristics: (1) monitoring and evaluation, which enhanced the instinctive expansion of the project's initial scope. This led to (2) innovative problemsolving skills that enabled (3) collaborative capacity building enshrined in government-industry and transboundary trade-offs. In summary, Table 3 depicts that the team's characteristic of consistency, resourcefulness, and flexibility, which often seems disintegrative, is crucial for a long-term coordination process.

This article further provides an empirical contribution to coordination theory associated with a long-term incident management system. In practical terms, this study also contributes to the network analytical approach. This approach adds to the network structural characteristics with observational network interactions units, which include the nodes and position of role players, identify the nature of relations, and reveal the presence or absence of interactive links (Provan and Kenis 2008).

Similar to the application of the ICS in disaster response, this study indicates that incident management complexity is recognized during the preparedness and risk reduction phases of disaster management. Shared values, collective cognitive resources, commitment, and trust are equally important throughout all the stages of disaster management. Correspondingly, the findings indicate that the process of developing an IMS in the South African context is in line with Okhuysen and Bechky's (2009) interpretation of coordination as consisting of accountability, predictability, and common understanding. These elements were compromized by fragmented legislative mandates and limited oil spill response expertise, resulting in an inflexible and prolonged decision-making process. This is aligned to the perspective of Wolbers and his colleagues (2018) in that ambiguity and disjointedness are realities that often complicate incident and disaster management operations through incoherence, deviation, and contradictions. It can thus be reasoned that continuous discussion among stakeholders despite disagreements may create trust and a sense of power. Therefore, multiple interpretations of information are a resourceful decisionmaking process for it implies that everyone's opinion is considered and somehow democracy prevailed (Southern 2002). Such openness to multiple voices may be interpreted as an indication of mutual respect and trust. This behavioral practice will hence improve the sharing of resources crucial for effective coordination.

While dedicated to achieving an optimal level of coordination, the findings indicate that collective effort in pursuing practices of political commitment, bridging the gaps, and sharing resources could not be sufficient without additional steps. The findings demonstrate the importance of resourcefulness in dealing with ever-changing coordination demands, particularly for the long-term establishment of a sustainable IMS. In this section, the theoretical argument on coordination is expanded by specifying both characteristics and virtues of resourcefulness (Table 4). 
Table 4 Summary of resourcefulness implications for effective coordination in an Incident Management System

\begin{tabular}{|c|c|c|}
\hline Resourcefulness & Characteristics & Virtues (qualities) \\
\hline Monitoring and evaluation & Ensures accountability & Multiplicity, redundancy and diversity \\
\hline $\begin{array}{l}\text { Innovative problem-solving } \\
\text { skills }\end{array}$ & $\begin{array}{l}\text { Continued predictability and operability of the } \\
\text { system }\end{array}$ & Constant participation and implementation of the action plan \\
\hline $\begin{array}{l}\text { Collaborative capacity } \\
\text { building }\end{array}$ & Common understanding & $\begin{array}{l}\text { The commitment of different entities and stringent operational } \\
\text { procedures }\end{array}$ \\
\hline
\end{tabular}

Fig. 3 The monitoring and evaluation process that unfolded to ensure that accountability assurance was enabled throughout the Operation Phakisa project

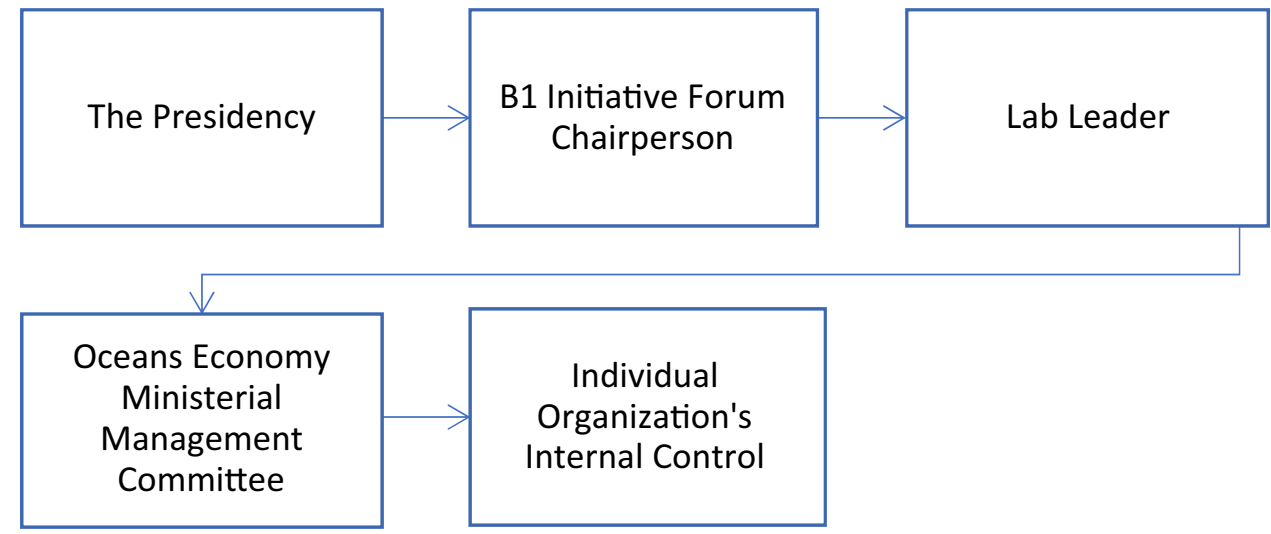

\subsection{Accountability: Resourcefulness through Monitoring and Evaluation}

Our findings confirm that political commitment is a critical factor in ensuring accountability. This is the way the monitoring and evaluation process unfolded to ensure that accountability assurance was enabled throughout the project:

- First, the establishment of Operation Phakisa was a presidential initiative with a directive, commanding the formation of a task team (B1 initiative) with a permanent chairperson appointed from the lead agency ${ }^{2}$ and answerable to the lab leader. ${ }^{3}$ This was to ensure that an individual or an organization can be held accountable for ensuring that project activities are effectively delivered.

- Second, the task team was answerable to the lab leader tasked to carry out the monitoring and evaluation role. Moreover, specific organs of state and industry associations were held accountable for their organizational contributions to the action plan and compulsory attendance of all meetings was closely monitored to ensure a quorum.

- Last, the Oceans Economy Ministerial Management Committee was approached to encourage consistent

\footnotetext{
2 An organ of state identified by the Presidency to lead the project.

${ }^{3}$ Lab-leader is an appointee from the Office of the Presidency.
}

participation and commitment. Thus, multiplicity, redundancy, and diversity for monitoring and evaluation were adopted for consistency and accountability of the tasks (Fig. 3).

Thus, monitoring and evaluation processes established through the initiative benefited the management of marine oil spills in ascertaining accountability. The roles and responsibilities identified, including participation in exercises, commenting on NOSCP, and training, were thus reasonably implemented.

\subsection{Predictability: Resourcefulness Through Innovative Problem-Solving Skills}

Beyond ascertaining accountability, our findings further indicate that the concept of attaining a reliable IMS depends on the ability to predict setoffs that will undermine the system's efficiency. This will enable the team to identify and implement mitigation-related tasks required for continuous stability and efficiency of the system. This finding contributes to the literature on organizational processes in line with the notion that disintegration limits shared conceptualization of required actions. This process offers a rapid and innovative problem-solving opportunity crucial for attaining operability and continued predictability of the incident management system (Wolbers et al. 2017). 
The initiative's commended characteristics are clear deadlines for tasks and fore-set dates for obligatory meetings. In addition to predictability, these plans, preconceived and timely communicated to the key stakeholders, contributed to constant participation. The findings further indicated that reaching this level of consistency and commitment demanded sustained gap analysis and investment in solutions for mending identified differences.

The approach adopted at the inception of the initiative, where the Presidency set aside six weeks of dialogue to design and refine the vision for the country in terms of the oil and gas industry, proved crucial to success. In addition to demonstrating political commitment, one of the primary determinations in this initial-vision gathering was to design an action plan that allowed for predictability.

The study findings further illustrate success in the operational collaboration of government officials assigned to participate in the initiative, because Operation Phakisa enabled predictability, commitment, and consistent action plans. This allowed for focus and dedication in developing the preparedness strategies and activities required for marine oil spill response. Yet, slow and limited vertical interactions persisted in some cases. This undermined the intended fast-paced service delivery strategy as originally envisioned. It may then be argued that while efforts for indepth planning is acknowledged, there was limited nurturing of common understanding for a robust multi-sectoral collaboration.

\subsection{Common Understanding: Resourcefulness Through Collaborative Capacity Building}

Coordination is defined here as the process of social and material interactions among interdependent organizations that share a common goal of community welfare (Drabek 2007). Coordination of actors serves to unify strategy (Jahre and Jensen 2010), reduce duplication of services (Nolte et al. 2012), and decrease the waste of resources (Okhuysen and Bechky 2009). In other words, the coordination process is a by-product of collaborative capacity building. In this study, the project team extended capacity building through joint gap analyses and agreement to focus on the end goals of the 3 -ft plan.

In retrospect, the approach required a pattern that encouraged the commitment of different entities to shared goals and stringent operational procedures in order to deliver the granular details of individual tasks. Nevertheless, collaboration development depends on cooperation beyond the hierarchical system. We argue from our findings that routine interactions will, over time, achieve a naturalized working relation. This observation is aligned with Grönholm's (2018) conviction that projects often generate new knowledge and flexible problem-solving opportunities that would otherwise not be resolved through the traditional hierarchical methods. Practically, participants of any operation or long-term project are concerned with sustainable implementation enabled by effective information diffusion to all players in national, regional, and local spheres.

It may be argued that from the inception stage of the Operation Phakisa initiative, the drafters acknowledged that the country is ill-prepared for the multi-sectoral complexity of cross-level cooperation. Perceived independencies, often linked to the autonomy of different spheres of government, act as an inherent barrier to systematic linkages and cross-level vertical collaboration. Through this initiative, regional proliferation has fostered general transparency and the sharing of best practices to enhance capacity building across the region.

Similarly, continuous consultation allowed participants to recognize misalignments of the existing plans and seek solutions for effective response pre-emptively. These solutions include establishing and aligning a national wildlife oil spill response plan with the National Oil Spill Contingency Plan (NOSCP). This exercise accomplished a coherent understanding of roles and responsibilities in planning and response between government and NGOs.

Moreover, in drafting the NOSCP, the importance of tier response has been outlined and revised from the previous regime that linked the tiered approach to the volume of oil spilled. The committee conducted a detailed oil spill response/resources capacity assessment thereby drafting a clear picture of the current capability. This was then commensurate with the activity and risk levels in the country. Based on this assessment, resources that the South Africa government has on disposal are categorized as tier 1 , those that will be sourced from nationally based third parties as tier 2, and those required from internationallybased third parties are categorised as tier 3. This tiered approach is erected against the backdrop of the unified response command with the structure enabled to expand based on the needs of the incident.

While there have been substantial strides in the development of marine oil spill management in the country, there is yet to be a significant incident that will effectively test the institutionalized management system's actual readiness and efficiency. It is nevertheless expected that the resourcefulness perspective presented in this article will be fruitfully applied in a rapid oil spill response setting. Unlike previous coordination studies that focused on organizational management (Opdyke et al. 2017), this study has contributed to coordination theory within the disaster risk management context. 


\subsection{Research Limitations}

This study was context-specific, with some limitations to external validity. The methodology employed may be adapted, however, for replication in countries where some form of development initiative like Operation Phakisa is functional, and the oil industry is developmental. While this study was developed based on the South African context, it provides the prospect for further research to test its applicability in other countries with a similar profile. The critical contextual sensitivity is on the legal framework, the institutional arrangements, and the organizational ethos.

Observation as a research method is complex, because the researcher has limited control over the suitability of the conditions that unfold. Similarly, if not well considered, the amount of data from observation may be complex and unmanageable with the risk of distortion. On the other hand, observation of the simulation exercises allowed an opportunity to collect data in a similar setup to what would be activated during an emergency and to consider a similar decision-making process. Although these benefits are considerable, the lack of fast-tracked and realistic scenarios was considered a limitation. In this study, the multiple methods adopted, including interviews and literature review, minimized these limitations. Long-term longitudinal studies could also be considered for the regional target to assess the applicability of this model.

\section{Conclusion and Recommendation}

There is a general sentiment that to comprehend a coordination process better, one must identify and understand network webs of resources, structures, and relationships. This study provides that the success and failure of the system are dependent on its resourcefulness. Similar to the fragmentation perspective in the introduction, multiplicity, redundancy, and diversity may provide the efficient monitoring and evaluation strength necessary for effective coordination. During the response phase of an incident, predictability is associated with anticipating the next step. However, the analysis shows that innovative problemsolving skills provide a level of certainty required for excellent incident coordination. The commitment of different entities and stringent operational procedures offer the opportunity to build collective capacity despite any uncommon misunderstanding that may persist. The ability to expand the initial project scope contributed to the nimble resourcefulness of the project structure, as did creation of resultant policy reform unconsciously and development of innovative problem-solving skills that enabled trade-offs between government and industry in the country and across the region. Thus, future studies should focus on engendering marine oil spill hazard risk reduction models with a powerful stance on the role of joint government-industry multi-level networks.

Acknowledgements This work was partially funded by the PostGraduate Bursary program of the North-West University.

Open Access This article is licensed under a Creative Commons Attribution 4.0 International License, which permits use, sharing, adaptation, distribution and reproduction in any medium or format, as long as you give appropriate credit to the original author(s) and the source, provide a link to the Creative Commons licence, and indicate if changes were made. The images or other third party material in this article are included in the article's Creative Commons licence, unless indicated otherwise in a credit line to the material. If material is not included in the article's Creative Commons licence and your intended use is not permitted by statutory regulation or exceeds the permitted use, you will need to obtain permission directly from the copyright holder. To view a copy of this licence, visit http://creativecommons. org/licenses/by/4.0/.

\section{References}

Bahrami, P., A. Ardalan, A. Nejati, A. Ostadtaghizadeh, and A. Yari. 2020. Factors affecting the effectiveness of hospital incident command system; findings from a systematic review. Bulletin of Emergency and Trauma 8(2): 62-76.

Bigley, G.A., and K.H. Roberts. 2001. The incident command system: High-reliability organising for complex and volatile task environments. Academy of Management Journal 44(6): 1281-1299.

Boersma, K., L. Comfort, J. Groenendaal, and J. Wolbers. 2014. Incident command systems: A dynamic tension among goals, rules and practice. Journal of Contingencies and Crisis Management 22(1): 1-4.

Buck, D.A., J.E. Trainor, and B.E. Aguirre. 2006. A critical evaluation of the incident command system and NIMS. Journal of Homeland Security and Emergency Management 3(3): Article 1.

Bunge, M., and R. Ardila. 1987. The social matrix of behavior. In Philosophy of psychology, ed. M. Bunge, and R. Ardila, 221-232. New York: Springer.

Chang, H.H. 2015. An analysis of incident command system. Doctoral dissertation. University of Delaware, Newark, DE, USA.

Comfort, L.K., and N. Kapucu. 2006. Inter-organisational coordination in extreme events: The World Trade Center attacks, September 11, 2001. Natural Hazards 39(2): 309-327.

Drabek, T.E. 2007. Social problems perspectives, disaster research and emergency management: Intellectual contexts, theoretical extensions, and policy implications. Denver, CO: Department of Sociology and Criminology, University of Denver.

Dwivedi, Y.K., M.A. Shareef, B. Mukerji, N.P. Rana, and K.K. Kapoor. 2018. Involvement in emergency supply chain for disaster management: A cognitive dissonance perspective. International Journal of Production Research 56(21): 6758-6773.

GIWACAF (Global Initiative for West, Central and Southern Africa). 2019. Country profile 2019-South Africa. https://www.giwacaf. net/en/countries/south-africa. Accessed 05 Dec 2021.

Grönholm, S. 2018. A tangled web: Baltic Sea Region governance through networks. Marine Policy 98: 201-210. 
Jahre, M., and L.-M. Jensen. 2010. Coordination in humanitarian logistics through clusters. International Journal of Physical Distribution \& Logistics Management 40(8/9): 657-674.

Jones, C., W.S. Hesterly, and S.P. Borgatti. 1997. A general theory of network governance: Exchange conditions and social mechanisms. Academy of Management Review 22(4): 911-945.

Lutz, L.D., and M.K. Lindell. 2008. Incident command system as a response model within emergency operation centers during Hurricane Rita. Journal of Contingencies and Crisis Management 16(3): 122-134.

Moynihan, D.P. 2009. The network governance of crisis response: Case studies of incident command systems. Journal of Public Administration Research and Theory 19(4): 895-915.

Nolte, I.M., E.C. Martin, and S. Boenigk. 2012. Cross-sectoral coordination of disaster relief. Public Management Review 14(6): 707-730.

Noori, N.S., J. Wolbers, K. Boersma, and X. Vilasís-Cardona. 2016. A dynamic perspective of emerging coordination clusters in crisis response networks. In Proceedings of the 13th International Conference on Information Systems for Crisis Response and Management, 22-25 May 2016, Rio de Janeiro, Brazil.

Odeku, K.S. 2021. An analysis of "Operation Phakisa" to unlock the potential of ocean resources in South Africa. Journal of Asian and African Studies 56(2): 382-394.

Okada, A., and K. Ogura. 2014. Japanese disaster management system: Recent developments in information flow and chains of command. Journal of Contingencies and Crisis Management 22(1): $58-62$.

Okhuysen, G.A., and B.A. Bechky. 2009. Coordination in organisations: An integrative perspective. The Academy of Management Annals 3(1): 463-502.

Opdyke, A., F. Lepropre, A. Javernick-Will, and M. Koschmann. 2017. Inter-organisational resource coordination in post-disaster infrastructure recovery. Construction Management and Economics 35(8-9): 514-530.
Provan, K.G., and P. Kenis. 2008. Modes of network governance: Structure, management, and effectiveness. Journal of Public Administration Research and Theory 18(2): 229-252.

Rice, D.O. 2009. Improving emergency responder situational awareness for incident command systems (ICS) using critical information management, simulation, and analysis. In Proceedings of 2009 IEEE Conference on Technologies for Homeland Security, 11-12 May 2009, Waltham, Massachusetts, 640-646.

Rolan, R.G., and K.H. Cameron. 1991. Adaptation of the incident command system to oil spill response during the American Trader spill. In Proceedings of the 1991 International Oil Spill Conference (Prevention, Behavior, Control, Cleanup), 4-7 March 1991, San Diego, California, ed. J. Ludwigson, 267-272. Washington, DC: American Petroleum Institute.

Schwartz-Shea, P., and D. Yanow. 2009. Reading and writing as method: In search of trustworthy texts. In Organisational ethnography: Studying the complexities of everyday life, ed. S. Ybema, D. Yanow, H. Wels, and F.H. Kamsteeg, 56-82. London: SAGE Publications.

Sharma, R.K., B.R. Gurjar, A.V. Singhal, S.R. Wate, S.P. Ghuge, and R. Agrawal. 2015. Automation of emergency response for petroleum oil storage terminals. Safety Science 72: 262-273.

Shibutani, T. 2017. Society and personality: Interactionist approach to social psychology. New York: Routledge.

Southern, R. 2002. Understanding multi-sectoral regeneration partnerships as a form of local governance. Local Government Studies 28(2): 16-32.

Thornberg, R. 2017. Grounded theory. In The BERA/SAGE handbook of educational research, ed. D. Wyse, N. Selwyn, E. Smith, and L. Suter, 355-375. London: SAGE Publications.

Wolbers, J., K. Boersma, and P. Groenewegen. 2018. Introducing a fragmentation perspective on coordination in crisis management. Organisation Studies 39(11): 1521-1546. 